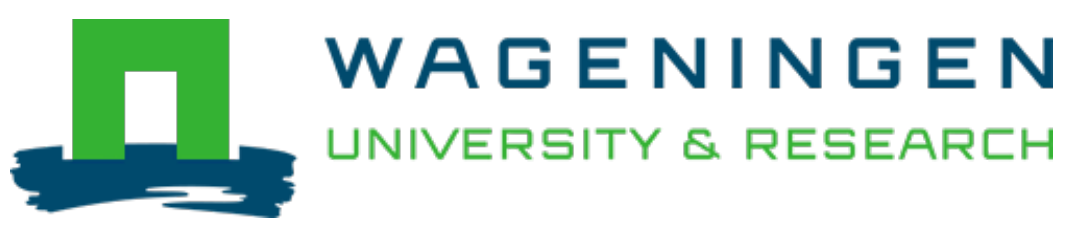

\title{
Clonal diversity and genetic differentiation of Maianthemum bifolium among forest fragments of different age
}

\author{
Plant Ecology \\ Arens, P.F.P.; Grashof-Bokdam, C.J.; Sluis, T.; Smulders, M.J.M. \\ https://doi.org/10.1007/s11258-004-7510-4
}

This article is made publicly available in the institutional repository of Wageningen University and Research, under the terms of article $25 \mathrm{fa}$ of the Dutch Copyright Act, also known as the Amendment Taverne. This has been done with explicit consent by the author.

Article 25 fa states that the author of a short scientific work funded either wholly or partially by Dutch public funds is entitled to make that work publicly available for no consideration following a reasonable period of time after the work was first published, provided that clear reference is made to the source of the first publication of the work.

This publication is distributed under The Association of Universities in the Netherlands (VSNU) 'Article $25 \mathrm{fa}$ implementation' project. In this project research outputs of researchers employed by Dutch Universities that comply with the legal requirements of Article $25 \mathrm{fa}$ of the Dutch Copyright Act are distributed online and free of cost or other barriers in institutional repositories. Research outputs are distributed six months after their first online publication in the original published version and with proper attribution to the source of the original publication.

You are permitted to download and use the publication for personal purposes. All rights remain with the author(s) and / or copyright owner(s) of this work. Any use of the publication or parts of it other than authorised under article $25 \mathrm{fa}$ of the Dutch Copyright act is prohibited. Wageningen University \& Research and the author(s) of this publication shall not be held responsible or liable for any damages resulting from your (re)use of this publication.

For questions regarding the public availability of this article please contact openscience.library@,wur.nl 


\title{
Clonal diversity and genetic differentiation of Maianthemum bifolium among forest fragments of different age
}

\author{
P. Arens ${ }^{1, *}$, C.J. Grashof-Bokdam ${ }^{2}$, T. van der Sluis ${ }^{2}$ and M.J.M. Smulders ${ }^{1}$ \\ ${ }^{1}$ Department of Biodiversity and Breeding, Plant Research International, Wageningen UR, P.O. Box 16, \\ NL-6700 AA Wageningen, The Netherlands; ${ }^{2}$ Department of Landscape Ecology, Alterra, Wageningen UR, \\ P.O. Box 47, NL-6700 AA Wageningen, The Netherlands; *Author for correspondence (e-mail: \\ paul.arens@wur.nl; phone: +31-317476981;fax:+31-317418094)
}

Received 30 June 2003; accepted in revised form 2 December 2004

Key words: Dispersal, Forest species, Genet, Mantel test, Population differentiation, Spatial pattern

\begin{abstract}
Maianthemum bifolium Schmidt (May Lily) is a woodland species with low colonisation ability and high demands for seedling establishment conditions. To study the colonisation process, we analysed the clonal organisation and population structure of Maianthemum bifolium populations in a number of forest fragments using AFLP. A total of 129 genets were identified. Most (41/53) patches of M. bifolium in recent (less than 80 years old) and old (at least 175 years of age) parts of the woodlands contained single genets. Only one of the 12 patches with multiple genotypes showed intermingled growth. Besides seed dispersal also dispersal of vegetative material contributed to colonisation since five genotypes were found in more than one patch, with patches up to $51 \mathrm{~m}$ apart. Population differentiation between populations in different forests was significant $\left(F_{\mathrm{ST}}=0.10\right)$ and indicated low gene flow. This level of differentiation was already found between populations in different parts of the same forest, just over $200 \mathrm{~m}$ apart. In fact, only two adjacent populations were not significantly differentiated, one population located in old forest whereas the other was established next to it on a former pasture re-forested after 1916. Limited gene flow is also consistent with the decrease of genetic similarities with physical distance, which relationship is highly significant but only for distances up to $400 \mathrm{~m}$.
\end{abstract}

\section{Introduction}

During the last centuries, the area of woodland in the agricultural landscapes of Northwest Europe has fluctuated considerably. At present, forest habitat in agricultural landscapes is fragmented into small woodlands. Large areas of the present woodlands consist of recent secondary woodlands, which were developed on former heathland, pastures or fields. Several studies have shown qualitative differences in the forest floor species composition between old and recently established woods (e.g. Peterken 1977; Hermy and Stieperaere 1981). Species composition and species richness of recent woods has been shown to depend on the distance to old woods, on the area and shape of the recent forest patch, and on the age of the forest patch (Dzwonko and Loster 1992; GrashofBokdam and Geertsema 1998). This has been attributed to the limited colonisation capacity of many woodland species and to their specific requirements for seedling establishment. These studies are based on correlations and give only a limited insight in the actual process of colonisation 
of plant species in fragmented forest habitat and how their life strategies affect colonisation. More knowledge on the colonisation capacity of woodland plants has been obtained by studying dispersal across an ecotone, which is the interface between old and recent forest (Brunet and Von Oheimb 1998; Bossuyt et al. 1999). In these studies, plants in the recent forest are assumed to originate from plants along the ecotone. Migration rates are estimated from the distance of the plants in the recent woodland to the ecotone in relation to the age of this woodland. For clonal plants colonisation may take place by vegetative propagation and/or seed dispersal and seedling establishment. Therefore, additional information on the colonisation processes may be obtained from genetic analysis of clonality and population differentiation.

One of the typical woodland plants of poor sandy soils in the Netherlands is Maianthemum bifolium (May lily). Maianthemum bifolium is a clonal long-living species and it is known to have a low dispersal capacity (Brunet and Von Oheimb 1998; Grashof-Bokdam and Geertsema 1998). Successful establishment by this species depends on the development of suitable soil conditions in young forest, which on former agricultural soils may take several decades. In dynamic and fragmented agricultural landscapes, it is therefore expected that destroyed populations are not easily replaced through colonisation from elsewhere while remnant populations may deteriorate due to a lack of rejuvenation. Together this could affect local and regional genetic diversity and thus the long-term survival of populations (Booy et al. 2000). To study the dynamics and evolution of such a clone-forming plant, discrimination of genets and detection of genetic variation among genets is an essential requisite (Torimaru et al. 2003).

Here we study local population establishment through the delineation of the spatial pattern of genets in M. bifolium populations. The study area comprised of forest fragments of different ages including two recent (1916) forest fragments that have an ecotone with adjacent older forest fragments. M. bifolium patches in these forest fragments have been analysed to estimate the number of genets and to study the pattern of genetic diversity with respect to mechanisms for maintaining clonal diversity. Furthermore we measured population differentiation and tested whether genetic similarities between individuals would decrease with geographical distance as estimates of gene flow.

\section{Material and methods}

\section{Species and study area}

Maianthemum bifolium Schmidt is a monocotyledonous, perennial clonal herb (Kawano et al. 1968). The plants are long-lived and spread predominantly vegetatively through sympodial, rhizomatous growth (Oinonen 1971). M. bifolium is self-sterile and seed set is generally very low (Kawano et al. 1968).

The study area is situated between Oldenzaal and Losser in the region of Twente, in the East of the Netherlands (Figure 1). For a detailed description see Grashof-Bokdam and Geertsema (1998). The study area was divided in six smaller areas $\mathrm{A}-\mathrm{F}$ each containing one or several connected forests. Soils are relatively dry and consist of loamy fine sand or loamy clay.

Woodland originating from before the 19th century consists mainly of wooded banks, which have been formerly used as barriers for cattle. Forest fragments are mostly remnants of forests that have been planted between 1850 and the beginning of the 20th century. These are partly deciduous and mixed forests planted on reclaimed heathland, but also on arable land and meadows. The study area is bordered by agricultural land and Picea plantations, so that it is unlikely that genetic exchange occurred between the studied populations and populations outside the area.

In 1994, presence/absence of $M$. bifolium, together with several other forest plant species, has been recorded in homogenous vegetation units of all forest fragments and wooded banks in the study area. For area A (Koksbos), the age and former use of each part of the forest was determined (Figure 1). For this, land register data have been combined with information from topographical maps of 1783, 1850 and 1916, and a detailed soil map. From area D (Smoddebos), which is a nature reserve, maps of age and former use were also available. Areas A and D both contain young forest fragments that were 


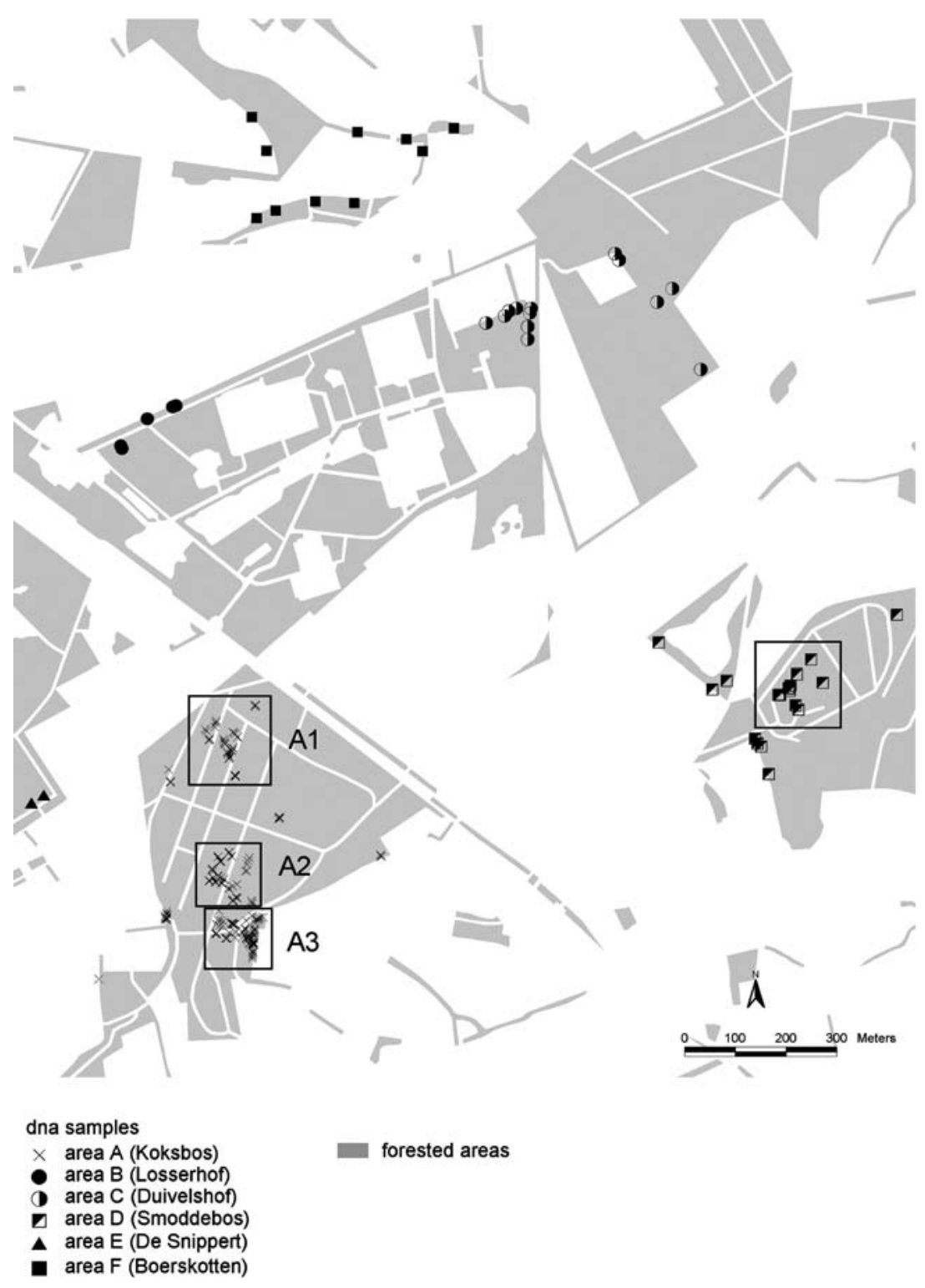

Figure 1. Study area between Oldenzaal and Losser in the Province of Overijssel, The Netherlands. In this area patches of Maianthemum bifolium have been sampled within forest areas A-F. Locations of area D within a box are located in young forest (after 1903).

established around 1916 and which form an ecotone with adjacent forest fragments that were already present before 1850 .

\section{Sampling}

All vegetation units containing $M$. bifolium have been surveyed in detail in 1997 to map the distribution of the species. M. bifolium shoots were always found in aggregations which were distinctly separate from each other. These aggregations are further referred to as patches. Most patches were relatively small, densely covered and clearly delimited except for two very large and sparsely covered patches in area A which were intermingled with other forest floor species.

Sampling for analysis of clonality within patches was focussed to areas A and D as previous research had shown a lack of genotypic diversity in 
small and isolated patches (Arens and Bijlsma, unpublished data). In these two areas $M$. bifolium patches were more abundant including some larger patches. In area A, samples were taken from three aggregated groups of patches and a number of isolated single patches (Table 1, Figure 1). Two of these groups (A1 and A3) consisted of patches in old forest and each included one of the two large patches. The third group (A2) consisted of smaller patches in the youngest (established after 1916) part of the forest and forms an ecotone with A3. In area $\mathrm{D}$, patches in the youngest (established after 1916) part of the wood formed the second ecotone with the surrounding forest. In area A and D leaf samples were taken at intervals of $1 \mathrm{~m}$ along a single transect within each patch. The only exceptions were the two large patches (in which two and four (Figure 2.) transects were sampled and where samples were more clustered). Assuming that the growth direction is unidirectional, the chosen sampling scheme with sampling along transects including the most distant samples should maximise the possibility to find different genotypes within patches. The number of samples depended on patch size, varying from 2 samples for patches below $1 \mathrm{~m}$ in diameter to 52 samples for the large patch in A3. In areas B, C, E and F patches were small and 1 sample per patch was collected for all existing patches except one. Locations of collected samples have been mapped in ARCVIEW (Esra). Migration distances along the ecotone were estimated by calculating the distance from patches in recent forest to the closest patch along the ecotone in old forest.

\section{AFLP analysis}

Young leaves were collected in $2 \mathrm{ml}$ Eppendorf tubes and directly frozen in liquid nitrogen. Samples were stored at $-80{ }^{\circ} \mathrm{C}$, lyophilised and grounded with 5-7 glass pearls in a Retch shaking mill prior to the DNA extraction. DNA was extracted using a plant DNA isolation kit (Qiagen).

AFLP was performed essentially as described by Vos et al. (1995). As most Liliaceae, Maianthemum bifolium has a large genome which leads to high numbers of bands in the standard AFLP procedure. To reduce the total numbers of bands detected, and improve unambiguous scoring, the AFLP protocol was adapted with respect to the number of selective nucleotides (Han et al. 1999). Pre-amplification was performed on primary template using a primer pair based on the sequences of the EcoRI and MseI adapter with one selective nucleotide at the $3^{\prime}$ end of the EcoRI primer and two selective nucleotides for the MseI primer. Selective amplification was performed with primers having three selective nucleotides for the EcoRI

Table 1. Summary data for the M. bifolium patches studied.

\begin{tabular}{|c|c|c|c|c|c|c|c|}
\hline Area & Sub-area & $\begin{array}{l}\text { Number } \\
\text { of patches }\end{array}$ & $\begin{array}{l}\text { Number of patches for } \\
\text { within patch clonality }\end{array}$ & $\begin{array}{l}\text { Number of } \\
\text { samples }\end{array}$ & $\begin{array}{l}\text { Number of } \\
\text { genotypes }\end{array}$ & $\begin{array}{l}\text { Type of } \\
\text { analysis }^{\mathrm{d}}\end{array}$ & $\begin{array}{l}\text { Age of forest stand } \\
(<\text { before },>\text { after })\end{array}$ \\
\hline \multirow[t]{4}{*}{ A } & A1 & 8 & $8(3)$ & 37 & $16^{\mathrm{c}}$ & $\mathrm{I}, \mathrm{P}, \mathrm{C}$ & $<1895$ \\
\hline & A2 & 18 & $18(3)$ & 40 & 16 & $\mathrm{I}, \mathrm{P}, \mathrm{C}$ & $>1916$ \\
\hline & A3 & 12 & $12(6)$ & 76 & $41^{\mathrm{c}}$ & $\mathrm{I}, \mathrm{P}, \mathrm{C}$ & $<1832$ \\
\hline & Other $^{\mathrm{a}}$ & 9 & $7(0)$ & 24 & 9 & $\mathrm{I}, \mathrm{C}$ & $<1895$ \\
\hline B & & 6 & 0 & 6 & 6 & I & \\
\hline $\mathrm{C}$ & & 14 & $1(0)$ & 15 & 14 & $\mathrm{I}, \mathrm{P}, \mathrm{C}$ & \\
\hline D & & 15 & $7(0)$ & 26 & 15 & $\mathrm{I}, \mathrm{P}, \mathrm{C}$ & $<1850,>1903^{\mathrm{e}}$ \\
\hline E & & 2 & 0 & 2 & 2 & I & \\
\hline $\mathrm{F}$ & & 10 & 0 & 10 & 10 & $\mathrm{I}, \mathrm{P}$ & \\
\hline Total & & 94 & $53(12)$ & 236 & 129 & & \\
\hline
\end{tabular}

${ }^{\text {a}}$ Patches sampled within area A but isolated from the three main groups.

${ }^{b}$ Number of patches used in the clonal analysis. Total number of samples taken per patch depended on patch size. Between brackets the number of patches with two or more genotypes.

${ }^{\mathrm{c}}$ Sub-areas A1 and A3 each included one of the two large patches of A. The large patch in A1 consisted of 8 genotypes, the large patch in $\mathrm{A} 3$ consisted of 24 genotypes.

${ }^{\mathrm{d}}$ Type of analyses for which samples were used. $\mathrm{I}=$ all genotypes were used to study the correlation between genetic and physical distances, $P=$ analyses of population differentiation, $\mathrm{C}=$ analyses of clonal organisation see $\mathrm{e}^{\mathrm{b}}$.

${ }^{\mathrm{e}} \mathrm{See}$ Figure 1 for location of patches within young forest of area D. 


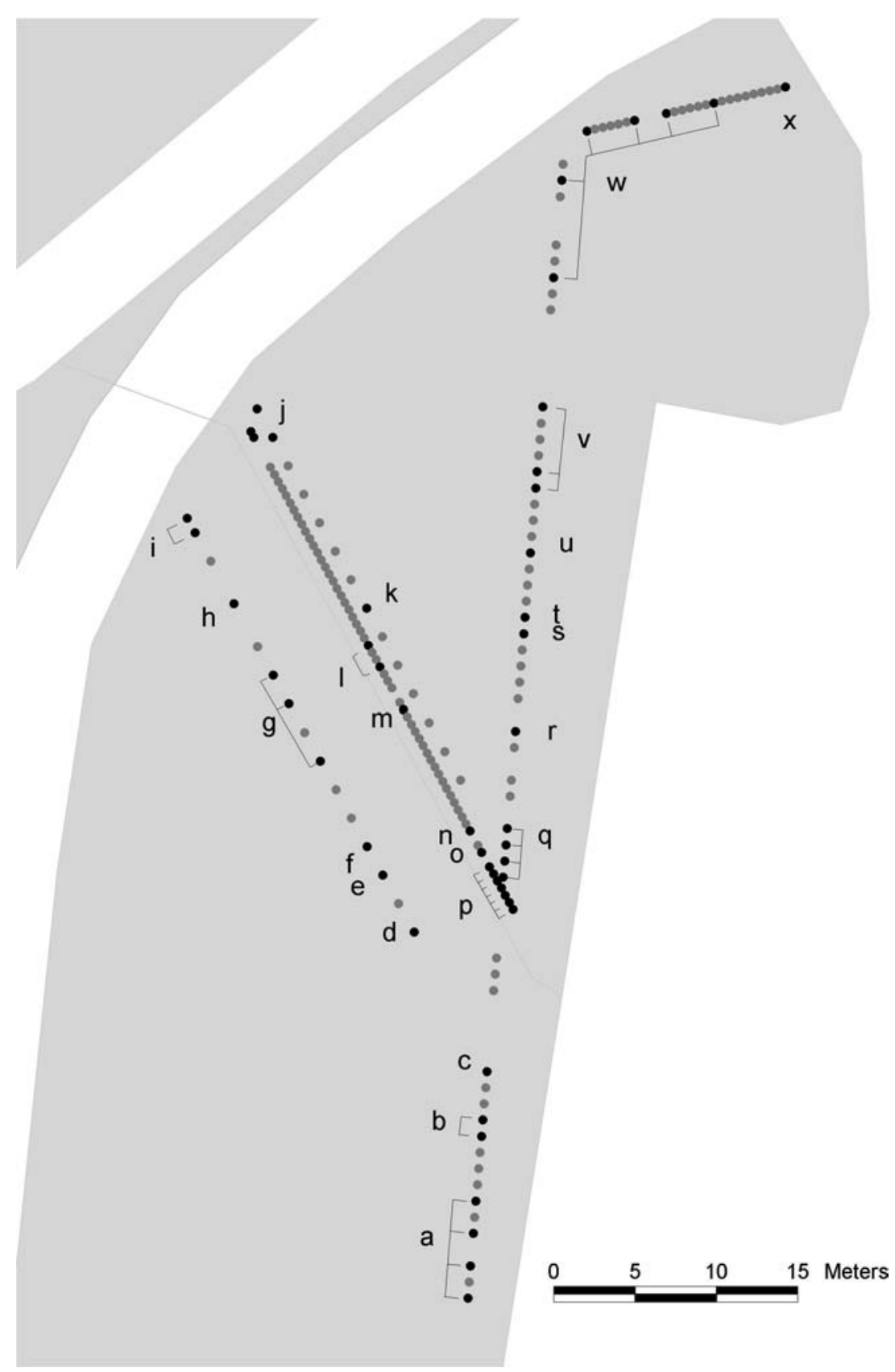

Figure 2. Genotype structure in the large M. bifolium patch within sub area A3. A total of 24 genotypes were identified among the 51 samples from this one patch, compared to 17 genotypes in the other 11 patches of A3 combined. Grey dots indicate unsampled May lily along transects, black dots indicate samples analysed by AFLP, and letters indicate different genotypes. Genotype W covered a stretch of $15 \mathrm{~m}$ whereas most genotypes only covered very small distances. Grey and black dots together indicate density of May lily plants along transects only.

adaptor and four selective nucleotides for the MseI adaptor. Samples have been analysed using five primer combinations with AGG/CCCT, ATC/ $\mathrm{CCCG}, \mathrm{ATC} / \mathrm{CCCC}, \mathrm{AAG} / \mathrm{CCCG}$ and $\mathrm{AAG} /$
CCCC as selective bases for the EcoRI and MseI site respectively. We tested reproducibility by estimating experimental and overall error as described previously (Arens et al. 1998). 


\section{Genetic analysis}

Only unambiguously scorable polymorphic AFLP bands (82 in total) were recorded. Presence (1) or absence $(0)$ of each of those polymorphic bands was recorded for all genotypes and band similarities between samples were calculated using simple matching.

Because of differences in the abundance and size of $M$. bifolium patches in the areas studied, different subsets of samples were used for the analysis of clonality, dispersal and population differentiation (Table 1). For clonal analysis within patches, patch transects were analysed hierarchically. Samples in the middle and at both ends of transects were analysed first. When these samples were identical, transects were assumed to contain one genotype and were not further analysed. If samples from one patch contained different genotypes, all other samples from that patch were also analysed. In subsequent analyses, plants with similarities above 0.98 were considered to be identical and to belong to the same genotype (Arens et al. 1998 and see Discussion). In total, 236 samples were analysed from 94 patches.

Dispersal was studied using all genotypes in the study, both by looking at the presence of clones in different patches, and by studying the presence and location of pairs of plants with high genetic similarity, as these may be indicative of siblings or parent-offspring pairs. For these, we focussed on genetic similarities above 0.80 . Furthermore, genetic similarities between individuals were tested against geographical distance by a Mantel test. Inter-plant genetic similarities $(s)$ were plotted against their pair-wise distances $(d)$. An equation of the type $s=J+(I-J) e^{-K d}$ was fitted to the data (Grashof-Bokdam et al. 1998). In this expression $I$ denotes the average similarity at zero distance (at $d=0, s=I), J$ denotes the average similarity at infinite distance (at $d=\infty, s=J$ ). Inter-plant genetic similarity $s$ is expected to decrease exponentially (between $I$ and $J$ ) with interplant distance $\mathrm{d}$ and regression coefficient $K$. The significance of the fitted curve has been tested by a randomisation procedure (Mantel 1967) in which plant distances were reallocated randomly 1000 times.

Analysis of population differentiation was performed on those populations with at least 10 genotypes: A1, A2, A3, C, D and F (Figure 1, Table 1). Population differentiation estimates based on Weir and Cockerham (1994), exact tests of population differentiation, and Shannon's Index were calculated using TFPGA (Tools for Population Genetic Analyses TFPGA, http://herb.bio. nau.edu/ miller/tfpga. htm).

\section{Results}

\section{Clonal organisation}

Within the 236 samples a total of 129 genotypes were discerned. The clonal organisation of M. bifolium within patches was studied in areas A and D. In area D all plants within one patch belonged to the same genotype. The radius of the largest patch in the recent established part of this forest (approx. 80 years-old) was $7.35 \mathrm{~m}$, which corresponds to a theoretically minimum expansion rate of around $9 \mathrm{~cm}$ year $^{-1}$. Also in area A identical samples were found within most patches. The 18 patches in young forest (A2) each consisted of one genotype, except for three patches where two genotypes were found with genetic similarities of $0.71,0.61$ and 0.71 , respectively. Maximum radius of a genotype in this recent A2 part of the forest was $6.25 \mathrm{~m}$, which corresponds to a growth of $8 \mathrm{~cm} \mathrm{year}^{-1}$ (assuming the plant arrived immediately after the forest was planted some 80 years ago). In the older parts of area $\mathrm{A}$ (A1, A3 and isolated patches), 18 patches contained one genotype each whereas nine patches contained more than one genotype. Summarising, of the 53 patches studied for within-patch variation only 12 contained more than one genotype and only the largest three patches contained more than two genotypes. All patches with multiple genotypes were found in area $\mathrm{A}$, regardless of forest age, but only in combination with a high patch density and/or a patch area exceeding $30 \mathrm{~m}^{2}$. We think the identical genotypes are the result of clonal propagation, since the probability of identity by chance between genotypes in area A was only $4.1 \times 10^{-4}$.

More detailed information on clonal growth was obtained from two large patches. In both patches densely and less densely grown parts were present, and samples were taken from both parts. In the large patch of area $\mathrm{A} 1$, one genotype was found twice $9 \mathrm{~m}$ apart and separated by at least five other genotypes. This genotype was also found 
in an adjacent patch (34 $\mathrm{m}$ away). All individuals of this genotype were found along a wildlife track. All other genotypes in this large patch were only found locally and did not intermingle. In the large patch in area $\mathrm{A} 3$ none of the genotypes were found intermingled with others. Within this patch, 28 times two plants were found that belonged to the same genotype and all 28 times these plants were adjacent to each other (Figure 2). Finding higher levels of intermingled growth when employing a higher sample density therefore seems unlikely. Of the 94 patches analysed for clonality between patches, 82 contained genotypes that were found in that patch only. The remaining 12 patches contained a total of five genotypes that were present in at least two patches. One genotype was found in two patches in area $\mathrm{B}, 5 \mathrm{~m}$ from each other in a wooded bank. The other four genotypes were found in patches in area A, 13-51 m apart. Three of these four genotypes were found in the young forest A2. One of these genotypes was present in four different patches, up to $51 \mathrm{~m}$ apart.

Based on these results, the average migration distance of genotypes across the ecotone into recent forest was calculated at minimally $0.36 \mathrm{~m} \mathrm{year}^{-1}( \pm 0.14, n=16)$ for area $\mathrm{A}$, and $1.28 \mathrm{~m} \mathrm{year}^{-1}( \pm 0.32, n=7)$ for area $\mathrm{D}$.

\section{Pattern of genetic similarities}

The mean Shannon's index $\left(H_{0}=0.54\right)$ indicate that the M. bifolium population has a high genetic diversity. Genetic similarities between all pairs of plants showed a normal distribution with an average similarity of 0.64 (data not shown). Only $200(0.7 \%)$ pairs of plants had a similarity between 0.80 and 0.98 with only $10(0.03 \%)$ pairs between 0.90 and 0.98 . These plants are most likely sibs or parent/offspring pairs. Pairs of plants with genetic similarity $>0.80$ (clones excluded from analysis) were exclusively found within the same area with always one of the plants sampled in an old ( $\leq 1832$ ) part of the forest. The only exception was a pair of two plants that were $514 \mathrm{~m}$ apart in area $\mathrm{B}$ and $\mathrm{F}$ and that had a similarity of 0.81 . These two forest areas have been connected by forest in the past (before 1916). Within areas, 46 pairs of plants with high genetic similarities were found with an average distance between plants of $79 \mathrm{~m}$.
Most of these pairs were found in area A, mainly within the old forest A3. From that part of the forest also a number of high similarities were found with plants in the adjacent young forest A2 and with plants in the northern part A1. No high genetic similarities were found among patches in the young forest A2. Within patches, pairs of plants with high genetic similarity were only found in the large patch of A3.

In a statistical test for isolation by distance, genetic similarity between pairs of genets dropped with increasing distance (Figure 3). The fitted curve could not be reproduced from the existing similarities in 1000 randomisations of the physical distances between plants, indicating a highly significant effect $(p<0.001)$ of geographical distance on genetic similarity. The fitted curve showed a decrease in similarity starting from a distance of around $20 \mathrm{~m}$ and a clear point of inflexion around $400 \mathrm{~m}$, after which the value does not drop any further.

\section{Population differentiation}

From the correlation between genetic similarity and physical distance it can be concluded that gene flow only generates a significant increase of genetic similarity on relative small distances. Such a limited gene flow would lead to genetic isolation of patches of $M$. bifolium within forest fragments. To test this, the two groups of patches in old forest (sub area A1 and A3) and the group of patches in young (after 1916) forest (sub area A2) of area A, although at short distances from each other (Table 2), were included separately in an analysis of population differentiation. The $F_{\mathrm{ST}}$ level between the three sub areas was 0.077 (95\% C.I. 0.05-0.10) showing a significant overall population differentiation. Pairwise comparisons (Table 2) show moderate differentiation between the old northern subarea A1 and both the southern old subarea $\mathrm{A} 3\left(F_{\mathrm{ST}}=0.092\right)$ and the young subarea $\mathrm{A} 2\left(F_{\mathrm{ST}}=0.124\right)$. In contrast, differentiation between $\mathrm{A} 3$ and $\mathrm{A} 2$ was low $\left(F_{\mathrm{ST}}\right.$ of 0.038). Exact tests for population differentiation (Raymond and Rousset 1995) showed that A3 and A2 are not significantly differentiated $(p=0.22)$ whereas both forest parts are significantly different from the old northern part A1. 


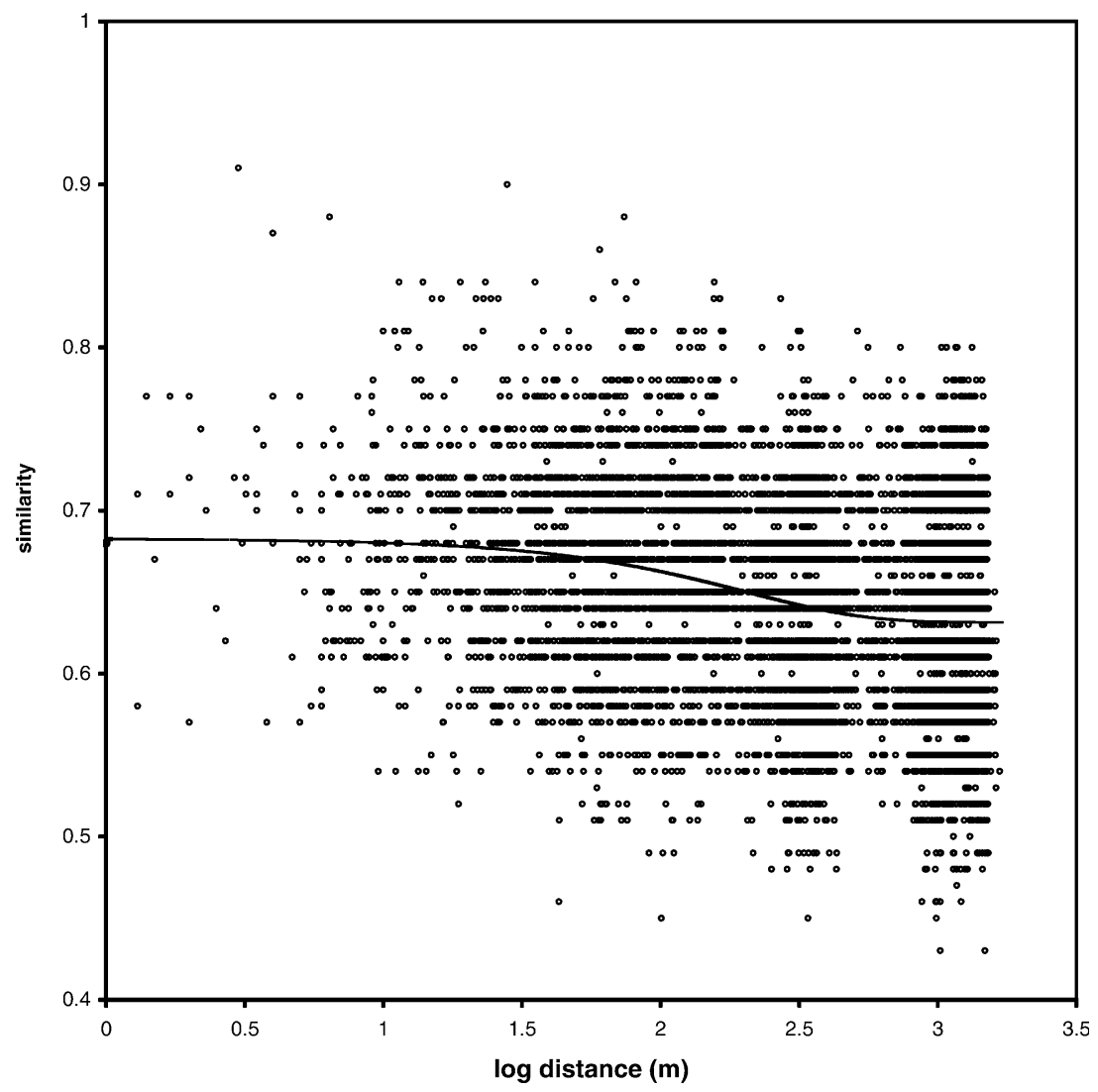

Figure 3. Genetic similarity $(s)$ vs. geographic distance $(d)$ between all pairs of genotypes in the study area. For the curve fitted to the data $s=J+(I-J) e^{-K d}$, the values $( \pm \mathrm{se})$ of the parameters are: $J=0.631 \pm 0.0093, I=0.682 \pm 0.0022, K=0.0048 \pm 0.00048$. The points show a somewhat striped pattern because the number of AFLP bands scored delimits the total number of possible similarity values.

Pairwise $F_{\mathrm{ST}}$ levels between these three sub areas and the other three areas $(\mathrm{C}, \mathrm{D}$ and $\mathrm{F})$ indicate an average level of population differentiation of 0.11 at distances of $570-1400 \mathrm{~m}$. The overall $F_{\mathrm{ST}}$ level among the six populations showed a significant population differentiation of 0.103 (95\% C.I. 0.081-0.127).

\section{Discussion}

\section{Clonal organisation}

While studying clonal growth, it is of prime importance to identify plants with identical genotypes. Previous studies, looking at the

Table 2. Genetic $\left(F_{\mathrm{ST}}\right)$ and physical distances between areas.

\begin{tabular}{|c|c|c|c|c|c|c|}
\hline Population & A1 & $\mathrm{A} 2$ & A3 & $\mathrm{C}$ & $\mathrm{D}$ & $\mathrm{F}$ \\
\hline Al & - & 217 & 301 & 1025 & 950 & 1100 \\
\hline A2 & 0.1236 & - & 88 & 1088 & 1144 & 1321 \\
\hline A3 & 0.0918 & $0.0376^{*}$ & - & 1095 & 1207 & 1404 \\
\hline $\mathrm{C}$ & 0.1702 & 0.1251 & 0.0981 & - & 808 & 1359 \\
\hline $\mathrm{D}$ & 0.1452 & 0.0934 & 0.1001 & 0.1130 & - & 571 \\
\hline $\mathrm{F}$ & 0.1540 & 0.1399 & 0.1042 & 0.1100 & 0.1003 & - \\
\hline
\end{tabular}

*Not significant in exact test for population differentiation.

Above diagonal: geographical distance between the centre of the areas in metres, below diagonal pairwise $F_{\mathrm{ST}^{-}}$values between areas. All values are significant $(95 \%$ C.I.) except one. 
reproducibility of AFLPs (Arens et al. 1998; Becker et al. 1995; Douhovnikoff and Dodd 2003) have shown that plants having almost identical banding patterns $(>0.98)$ can be considered clones, the few differences being caused by small flaws in the experimental procedure. In this study, genetic similarity above 0.98 was rare and restricted to adjacent samples. Genetic similarities between 0.90 and 0.98 were very few $(0.03 \%)$. This distribution is in accordance to the self-incompatible nature of the species and we have therefore assumed all similarities above 0.98 to be artefacts of the AFLP analysis and treated these plants as one genet.

Part of this study was aimed at the general clonal structure within and between patches in relation to forest age. Preliminary results from a M. bifolium population study (Arens and Bijlsma, unpublished data) showed that small and/or relatively isolated patches mostly consisted of just one genotype. In that study, 16 out of the 18 patches with a diameter smaller than $5 \mathrm{~m}$ contained just one genotype whereas this was found in just 16 out of the 46 patches larger than $5 \mathrm{~m}$. Within the present study most patches were small. Therefore, we decided to focus our analysis of genotypic diversity at the general clonal structure within and between patches and study more patches, instead of a detailed within-patch analysis of just a few patches. The results of the present study show a similar pattern as the previous study, with most samples from one patch being genetically identical and only $22 \%$ of the patches (in area A) showing multiple genotypes. Most of these patches were in high patch density areas with relatively larger patch sizes occurring in forest of various age indicating that clonal diversity correlates to patch size and/or density, rather than forest age per se. The fact that the total number of genotypes present in the large patches was probably underestimated strengthens this relationship. In contrast, Kreher et al. (2000) found, using a similar sampling scheme, that despite apparent clonal growth $91 \%$ of their Vaccinium stamineum patches contained more than one genet and in $32 \%$ of the patches all sampled individuals were different genets. Differences in life history traits most likely underlie this difference in clonal structure. Although M. bifolium genotypes can cover areas as large as $100 \mathrm{~m}^{2}$ (Arens and Bijlsma, unpublished data) and rhizome lengths of $3.5 \mathrm{~m}$ have been reported in a fir forest (Czarnecka 1996), the vast majority of genotypes in our study were clearly demarcated. They nearly always covered small areas and only one case of intermingled growth of genotypes was found. Although rhizome lengths were not measured extensively in our study, we never observed rhizomes longer than $1 \mathrm{~m}$.

The clear demarcation of genotypes is in agreement with observations of Eriksson (1989) that repeated seedling recruitment (RSR: recruitment from seed into populations of already established adult clones) appears to be absent in $M$. bifolium. In contrast, in the typical RSR-species Anemore nemorosa, Stehlik and Holderegger (2000) found that $95 \%$ of the samples had a unique multilocus genotype, and many different genotypes occurred within one patch. Our findings on vegetative growth may be related to local soil conditions, as Czarnecka (1996) showed that vegetative growth in $M$. bifolium responds to particular environmental conditions. One reason for the growth demarcation could be a resource limitation, as shown for Maianthemum dilatatum by Lezberg et al. (2001). To elucidate which factors influence vegetative growth and intermingling of clones, a more extensive study of $M$. bifolium sites will be needed, in which forests with a large variation in light intensities and other resources should be compared.

In a small number of cases the same genotype occurred in different patches. This could be the result of either clonal growth followed by fragmentation into separate patches or direct dispersal of vegetative material. In the latter case, above ground rooted shoots could be dispersed by animals or humans, and subsequently root in a new location. No evidence for fragmentation of large clones into smaller patches was found as most patches consisted of small, sharply demarcated sites. The estimated clonal growth rate between $0.3 \mathrm{~m} \mathrm{year}^{-1}$ (Brunet and Von Oheimb 1998) and $0.08-0.09 \mathrm{~m} \mathrm{year}^{-1}$ (this study) indicates that a long time would be needed to generate the large distances between patches of the same genotype. Three out of the five genotypes present in two or more patches were found in young forest, in which sufficient time for clonal growth and subsequent fragmentation is simply lacking. Therefore, these patches are most likely the result of dispersal of vegetative shoots.

The number of genotypes found in more than one patch and the distances, up to $51 \mathrm{~m}$, between 
those patches indicate that clonal dispersal is relevant at the scale of ecotone studies and has contributed to the colonisation of the young forest A2. For comparison, the distance from the ecotone to the farthest patch in A2 is $55 \mathrm{~m}$. In maximally 80 years this would correspond to an average migration of $0.69 \mathrm{~m} \mathrm{year}^{-1}$ or twice the dispersal distance by growth $\left(0.34 \mathrm{~m} \mathrm{year}^{-1}\right)$ estimated by Brunet and Von Oheimb (1998). However, it is very similar to the longest distance $(51 \mathrm{~m})$ between ramets found within this young forest, for which dispersal of vegetative shoots appears the likely mechanism.

\section{Genetic similarity and population differentiation}

The distribution of similarities is in agreement with expectations for self-incompatible species. Accordingly, the mean Shannon's index is comparable to values recorded for other long-lived outcrossing species (Persson and Gustavsson 2001). High genetic similarity $(>0.80)$ between plants, which could indicate close relatedness or common ancestry, is almost completely limited to pairs of plants which occur in the same forest at relatively close distances from each other. Isolation-by-distance was significant up to $400 \mathrm{~m}$, after which genetic similarity levels reached the background levels of unrelated individuals and the correlation between geographical and genetic distance is no longer present. The seemingly stable relationship between similarity and distance before a possible first point of inflexion around $20 \mathrm{~m}$ (Figure 3) may be an artefact, due to the low number of patches at smaller distances and to the fact that geographic distance between patches was calculated between the centres of the patches, which precludes very small distances. The maximum decrease of the genetic similarity $(5.1 \%)$ from the most related pair of plants to the average genetic similarity between plants is small compared to e.g. Lonicera periclymenum where a decrease of $12 \%$ was found by Grashof-Bokdam et al. (1998). This is probably due to the fact that $M$. bifolium is self-incompatible and high genetic similarities thus are very rare. Nevertheless, the decrease is highly significant $(p<0.001)$ and shows that gene flow is already limited by short distances and only has an effect on genetic similarity up to $400 \mathrm{~m}$.
The isolation-by-distance results are consistent with those from the population differentiation tests. Although there is some gene flow across short distances it cannot prevent populations from differentiating significantly. Population A2 was significantly differentiated from population A1, which is $200 \mathrm{~m}$ away. Moreover, the populations A1 and A3, although from old forest parcels (dating between 1795 and 1895) and currently within the same forest (from 1916 onwards), are genetically isolated from each other although just $300 \mathrm{~m}$. apart. Overall $F_{\mathrm{ST}}$-levels show that genetic differentiation between areas, at this small geographical scale, is moderate to high. This is consistent with populations that have persisted as remnants in wooded banks and in small forest fragments with limited gene flow among them. These results correspond to the small migration distances found for $M$. bifolium in ecotone studies (Brunet and Von Oheimb 1998) and are consistent with the dispersal distances as estimated from the average distance between colonised woodlots and the nearest occupied old woodlot in distribution studies (Grashof-Bokdam and Geertsema 1998).

\section{Reproductive strategy and conservation issues}

The relative poor colonisation rate of $M$. bifolium in fragmented landscapes may be related to the species' life history traits. Worthen and Stiles (1988) suggested that low gene flow levels could be the result of limited pollen flow in Maianthemum canadense. Pollen limitation is typical for early spring flowering plants, which flower before large populations of pollinators are available (Schemske et al. 1978). Sexual reproduction within populations and between nearby populations may also be limited by the species' self-incompatibility. This could explain the low fruit set observed in our populations and reported in other studies (e.g. Kawano et al. 1986; Eriksson and Ehrlén 1992), although also local abiotic factors (light, humidity) may influence seed set (Kawano et al. 1968; Ietswaart and Schoorl 1985). Despite the species' apparent low recruitment rate, genetic diversity within young and old populations was high. Pappert et al. (2000) proposed two scenarios to produce this kind of genotypic diversity within populations of clonal plants. Either, populations may start with relatively few founders but 
subsequent pollen flow and seedling establishment could introduce additional genotypic diversity into populations. Or, several individuals from different sources may establish themselves, starting a population with high levels of genotypic diversity. A number of species-specific properties point in the direction of the second scenario. M. bifolium is not capable of repeated seedling recruitment (Eriksson 1989). Furthermore, when starting from a low number of genotypes, the species self-incompatibility and clonal growth would hamper the development towards the genotypic structures found within these populations. Successful seed recruitment therefore probably derives from seeds germinating simultaneously, within a certain period (window of opportunity) in the history of the forest remnants when conditions for seed set and recruitment are particularly favourable. After initial colonisation, individual plants grow clonally and may occupy a micro-niche, in time some plants may contact each other so that a larger patch with several genotypes develops. In the absence of differences in fitness, coexistence of genotypes may be maintained over relatively long periods of time, and competitive exclusion may be delayed by intraclonal aggregation. This would be consistent with the finding that the size of genotypes in patches with multiple clones is relatively small and clone sizes are more or less similar. On a long time scale the recruitment strategy, although depending on very rare processes, combined with the species longevity and ability for clonal growth has been very successful in natural forest habitats. According to Hultén (1962) M. bifolium is one of the most common plants in Eurasiatic coniferous woods.

In current agricultural landscapes, however, with a very dynamic and fragmented forest habitat, the ability of $M$. bifolium to colonise reforested areas may be too limited to compensate the increased population turnover. This and other studies (Grashof-Bokdam 1997a; Grashof-Bokdam and Geertsema 1998; Jacquemyn et al. 2001; Van Ruremonde and Kalkhoven 1991) have shown that gene flow and seed dispersal to recent secondary woodlands is strongly affected by distance. In fact, significant effects of gene flow were only detected on very short distances like for many zoochorous interior forest species (GrashofBokdam 1997b). As a consequence, old forest with a high density of $M$. bifolium patches is very valuable as potential seed source. Besides distance, seed production and micro-site limitations seem to affect colonisation rate (Eriksson and Ehrlén 1992). Further research should therefore focus on the specific conditions needed for seed set and seed recruitment, and the effect of forest management on vegetative growth and dispersal of vegetative material.

\section{Acknowledgements}

This study was funded by The Ministry of Agriculture, Nature Management and Food Quality and the Foundation DLO. We would like to thank Jolanda Dirksen for her assistance with fieldwork, Harold Kuipers for his assistance with ARCVIEW and Hans Jansen for his help with Genstat. Our thanks also to the property owners for allowing access to the populations and to two anonymous referees for valuable comments.

\section{References}

Arens P., Coops H., Jansen J. and Vosman B. 1998. Molecular genetic analysis of Black poplar (Populus nigra L.) along Dutch rivers. Mol. Ecol. 7: 11-18.

Becker J., Vos P., Kuiper M., Salamini F. and Heun M. 1995. Combined mapping of AFLP and RFLP markers in barley. Mol. Gen. Genet. 249: 65-73.

Booy G., Hendriks R.J.J., Smulders M.J.M., Van Groenendael J.M. and Vosman B. 2000. Genetic diversity and the survival of populations. Plant Biol. 2: 379-395.

Bossuyt B., Hermy M. and Deckers J. 1999. Migration of herbaceous plant species across ancient-recent forest ecotones in central Belgium. J. Ecol. 87: 628-638.

Brunet J. and Von Oheimb G. 1998. Migration of vascular plants to secondary woodlands in southern Sweden. J. Ecol. 86: 429-438.

Douhovnikoff V. and Dodd R.S. 2003. Intra-clonal variation and a similarity threshold for identification of clones: application to Salix exigua using AFLP molecular markers. Theor. Appl. Genet. 106: 1307-1315.

Czarnecka B. 1996. Clonal organisation of populations of Asarum europaeum and Maianthemum bifolium in contrasting woodland habitats. Vegetatio 125: 51-62.

Dzwonko Z. and Loster S. 1992. Species richness and seed dispersal to secondary woods in southern Poland. J. Biogeogr. 19: 195-204.

Eriksson O. 1989. Seedling dynamics and life histories in clonal plants. Oikos 55: 231-238.

Eriksson O. and Ehrlén J. 1992. Seed and microsite limitation of recruitment in plant populations. Oecologia 91: 360 364 
Grashof-Bokdam C.J. 1997a. Forest species in an agricultural landscape in the Netherlands: effects of habitat fragmentation. J. Veg. Sci. 8: 21-28.

Grashof-Bokdam C.J. 1997b. Colonization of forest plants: the role of fragmentation. PhD thesis, Wageningen.

Grashof-Bokdam C.J. and Geertsema W. 1998. The effect of isolation and history on colonisation patterns of plant species in secondary woodland. J. Biogeogr. 25: 837-846.

Grashof-Bokdam C.J., Jansen J. and Smulders M.J.M. 1998. Dispersal patterns of Lonicera periclymenum determined by genetic analysis. Mol. Ecol. 7: 165-174.

Han T.H., van Eck H.J., DeJeu M.J. and Jacobsen E. 1999. Optimization of AFLP fingerprinting of organisms with a large-sized genome: a study on Alstroemeria spp. Theor. Appl. Genet. 98: 465-471.

Hermy M. and Stieperaere H. 1981. An indirect gradient analysis of the ecological relationships between ancient and recent riverine woodlands to the south of Bruges (Flanders, Belgium). Vegetatio 44: 43-49.

Hultén E. 1962. The Circumpolar plants. Almquist and Wiksell, Stockholm.

Ietswaart J.H. and Schoorl J.W. 1985. Fructification in Dutch Maianthemum bifolium populations. Acta Bot. Neerl. 34: 381-391.

Jacquemyn H., Butaye J. and Hermy M. 2001. Forest plant species richness in small, fragmented mixed deciduous forest patches: the role of area, time and dispersal limitation. J. Biogeogr. 28: 801-812.

Kawano S., Ihara M. and Suzuki M. 1968. Biosystematic studies on Maianthemum (Liliaceae-Polygonatae) II. Geography and ecological life history. Jpn. J. Bot. 20: 35-65.

Kreher S.A., Foré S.A. and Collins B.S. 2000. Genetic variation within and among patches of the clonal species, Vaccinium stamineum L. Mol. Ecol. 9: 1247-1252.

Lezberg A.L., Halpern C.B. and Antos J.A. 2001. Clonal development of Maianthemum dilatatum in forests of differing age and structure. Can. J. Bot. 79: 1028-1038.

Mantel N. 1967. The detection of disease clustering and a generalized regression approach. Cancer Res. 27: 209220 .
Oinonen E. 1971. The time table of vegetative spreading in oak fern (Carpogymnia dryopteris L.) and May lily (Maianthemum bifolium L.) in Southern Finland. Acta Forestalia Fennica 118: 3-37.

Pappert R.A., Hamrick J.L. and Donovan L.A. 2000. Genetic variation in Pueraria lobata (Fabaceae), an introduced, clonal, invasive plant of the southeastern United States. Am. J. Bot. 87: 1240-1245.

Persson H.A. and Gustavsson B.A. 2001. The extent of clonality and genetic diversity in lingonberry (Vaccinium vitisidaea L.) revealed by RAPDs and leaf-shape analysis. Mol. Ecol. 10: 1385-1397.

Peterken G.F. 1977. Habitat conservation priorities in British and European woodlands. Biol. Conserv. 6: 239-245.

Raymond M.L. and Rousset F.1995. An exact test for population differentiation. Evolution 49: 1280-1283.

Schemske D.W., Willson M.F., Melampy M.N., Miller L.J., Verner L., Schemske K.M. and Best L.B. 1978. Flowering ecology of some spring woodland herbs. Ecology 59: 351366.

Stehlik I. and Holderegger R. 2000. Spatial genetic structure and clonal diversity of Anemore nemorosa in late successional deciduous woodlands of Central Europe. J. Ecol. 88: 424 435.

Torimaru T., Tomaru N., Nishimura N. and Yamamoto S. 2003. Clonal diversity and genetic differentiation in Ilex leucoclada M. patches in an old-growth beech forest. Mol. Ecol. 12: 809-818.

Van Ruremonde R.H.A.C. and Kalkhoven J.T.R. 1991. Effects of woodlot isolation on the dispersion of plants with fleshy fruits. J. Veg. Sci. 2: 377-384.

Vos P., Hogers R. and Bleeker M. et al. 1995. AFLP: a new technique for DNA fingerprinting. Nucleic Acids Res. 23: 4407-4414.

Weir B.S. and Cockerham C.C. 1994. Estimating $F$-statistics for the analysis of population structure. Evolution 38: 13581370 .

Worthen W.B. and Stiles E.W. 1988. Pollen limited fruit set in isolated patches of Maianthemum canadense Desf. in New Jersey. Bull. Torrey Bot. Club 115: 299-305. 